\title{
Wound FRP for Concrete Beams with Optimised Geometries
}

\author{
Yuanzhang Yang ${ }^{1}$, John Orr $^{2}$ and Saverio Spadea ${ }^{3}$ \\ ${ }^{1}$ University of Bath, BRE Centre for Innovative Construction Materials, Bath, BA2 \\ 7AY, UK; email: yy701@bath.ac.uk \\ ${ }^{2}$ University of Bath, BRE Centre for Innovative Construction Materials, Bath, BA2 \\ 7AY, UK; email: J.J.Orr@bath.ac.uk \\ ${ }^{2}$ University of Bath, BRE Centre for Innovative Construction Materials, Bath, BA2 \\ 7AY, UK; email: S.Spadea@bath.ac.uk
}

\begin{abstract}
Fabric formwork is a casting system that uses woven fabrics as the mould for concrete, utilising the fluidity of concrete to create optimised structural geometries. Fabric formed beams normally have variable depth along their longitudinal axis which makes it extremely time and labour consuming to install steel shear links because of this changing geometry. We propose the use of Wound Fibre Reinforced Polymer (WFRP) in which carbon fibres tows coated in wet epoxy matrix are wound around the longitudinal reinforcement to create uniquely shaped reinforcement cages as a practical alternative to steel shear links.

In this work, eight tapered beams with varying reinforcement ratios were tested. All the specimens have same clear span and shear span/depth ratio. The influence of the shear reinforcement ratio and the shear reinforcement pattern were investigated. A Modified Compression Field Theory (MCFT) model was built to simulate the performance of the tests. The design codes (ACI 440 and CSA S806) as well as the MCFT model were assessed by the testing results.

It is found that the application of WFRP in concrete beams is successful. The fabrication process of the reinforcement cage was easy to construct and enables the fabrication of reinforcement for optimised beam geometries. The test specimens failed in the predicted failure modes and the WFRP can increase shear capacity up to $250 \%$. The MCFT model works more accurately than the two design codes. The shear reinforcement pattern plays an important role in the shear design and there is great potential to optimise the WFRP pattern.
\end{abstract}

Keywords: WFRP, MCFT, optimisation, shear design

\section{INTRODUCTION}

Fabric formwork is a casting system using woven fabric as the container to form concrete (Veenendaal, West and Block, 2011). Utilising the gravity and fluidity, fabric formwork can create concrete structures with optimized geometries. These beams with optimised geometries normally have variable depths to achieve similar bending capacities along their longitudinal axis (Orr et al., 2011). However, fabrication of variable depth beam consumes massive labour and time because of installing shear links with different sizes and the bending of longitudinal bars (Bailiss, 2006). 
Wound Fibre Reinforced Polymer (WFRP) has been developed and used as the shear reinforcement of different types of beams. Fibre tows coated with epoxy matrix are wound around the mandrel made of longitudinal bars and after curing, the fibre reinforced polymer set as the shear reinforcement of the cage, as shown in Figure 1. This supplies great potential of applying WFRP in structurally optimised fabric formed concrete.

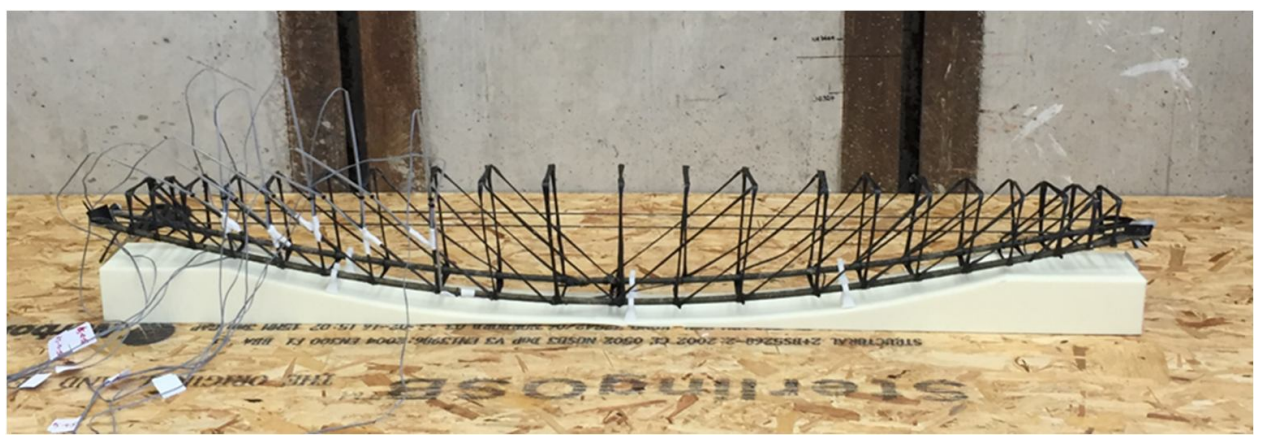

Figure 1. The WFRP cage for tapered beams

In this work, carbon fibres were used to make WFRP and in order to study the performance of the WFRP, eight tapered beam with optimised geometries were designed and tested. All specimens were designed with the same geometry. Different shear reinforcement arrangements were designed for all specimens. Predictions are calculated using two codes (ACI440 (2007) and CSA806-12 (2012)) and a Modified Compression Field Theory (MCFT) model which considered stress equilibrium, strain compatibility and material property of reinforcement (Vecchio and Collins, 1986).

\section{TEST DESIGN AND SETUP}

All specimens had the same width $(110 \mathrm{~mm})$ and length $(1500 \mathrm{~mm})$. The depth of the beams varied from $220 \mathrm{~mm}$ at mid-span to $139 \mathrm{~mm}$ at the support. The clear span was $1200 \mathrm{~mm}$ and the shear span was $400 \mathrm{~mm}$. The shear span/depth ratio was calculated with average effective depth and it was maintained as 2.5. The optimised geometry of all specimens was determined by the maximum curvature of longitudinal bars that can be maintained, as shown in Figure 2. Reinforcement ratios and patterns were chosen to investigate their influence on the shear performance of the specimens, as shown in Table 1 and Figure 3. LVDTs at the loading point and mid-span were used to measure displacement of the specimens. All specimens were loaded in three-point bending until failure.

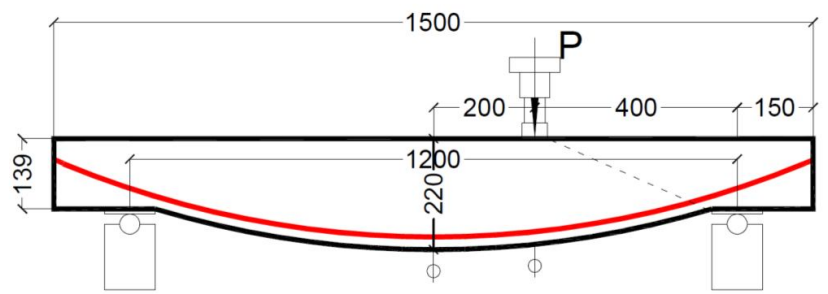

Figure 2. The geometry and test setup of the tapered specimens 
The cage was fabricated with four steps, 1) curving the longitudinal bars; 2) winding the carbon fibres; 3) resining the wound fibres; 4) curing. The first three steps were carried out by the author and for every cage, it took one person about three to four hours to finish the fabrication depending on the different volume of shear reinforcement. The curing of WFRP took 48 hours.

Table 1 . The design summary of specimens

\begin{tabular}{|c|c|c|c|c|c|c|c|}
\hline \multirow{2}{*}{$\begin{array}{l}\text { Speci } \\
\text { men }\end{array}$} & \multirow{2}{*}{$\begin{array}{c}\text { Flexural } \\
\text { bars }\end{array}$} & \multirow{2}{*}{$\begin{array}{l}\text { Mid-span } \\
\text { Effective } \\
\text { depth } d \\
\text { (mm) }\end{array}$} & \multicolumn{4}{|c|}{ Shear reinforcement } & \multirow[b]{2}{*}{$\begin{array}{l}\text { Expected } \\
\text { failure } \\
\text { mode }\end{array}$} \\
\hline & & & $\begin{array}{l}\text { Cross } \\
\text { section } \\
\text { area } \\
\left(\mathrm{mm}^{2}\right)\end{array}$ & $\begin{array}{l}\text { Distance } \\
\text { between } \\
\text { vertical } \\
\text { legs }(\mathrm{mm})\end{array}$ & $\begin{array}{l}\text { Angle of the } \\
\text { diagonal links } \\
\text { (degrees) }\end{array}$ & $\begin{array}{l}\text { Reinforc } \\
\text { ement } \\
\text { ratio }\end{array}$ & \\
\hline $\mathrm{T} 1$ & $2 \varphi 10$ & 195 & & & & & Shear \\
\hline $\mathrm{T} 2-1$ & $2 \varphi 10$ & 195 & 8.56 & 150 & $40-50$ & $0.25 \%$ & Shear \\
\hline $\mathrm{T} 2-2$ & $2 \varphi 10$ & 195 & 4.28 & 75 & $55-67$ & $0.25 \%$ & Shear \\
\hline T3-1 & $2 \varphi 10$ & 195 & 8.56 & 75 & $55-67$ & $0.50 \%$ & Shear \\
\hline T3-2 & $2 \varphi 10$ & 195 & 4.28 & 35 & $71-79$ & $0.51 \%$ & Shear \\
\hline $\mathrm{T} 4$ & $2 \varphi 10$ & 195 & 25.64 & 150 & $40-50$ & $0.75 \%$ & Bending \\
\hline T5-1 & $2 \varphi 10$ & 195 & 4.28 & $38-60$ & 45 & $0.50 \%$ & Shear \\
\hline T5-2 & $2 \varphi 10$ & 195 & 4.28 & $57-90$ & 45 & $0.30 \%$ & Shear \\
\hline
\end{tabular}
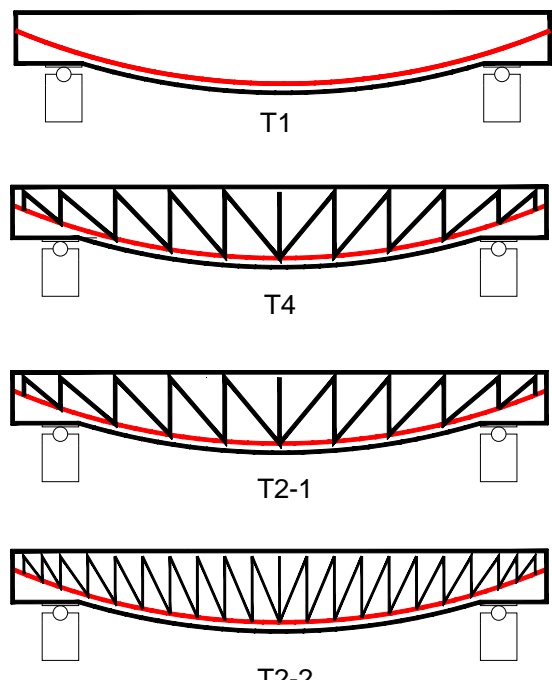

T2-2
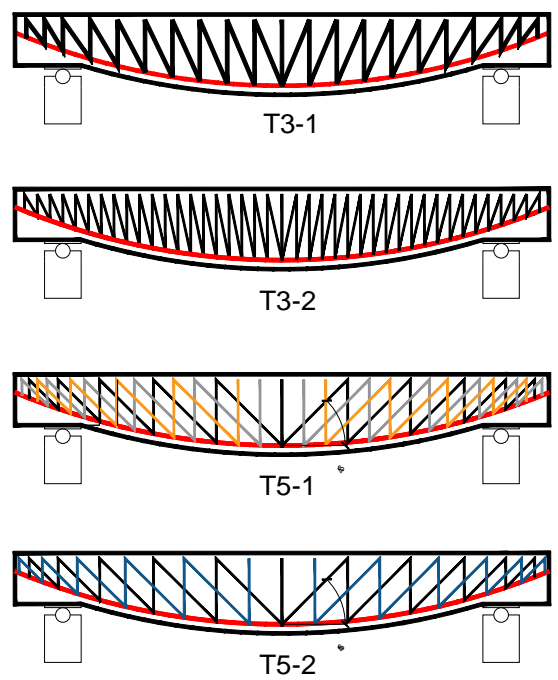

Figure 3. The WFRP patterns of different specimens

The average experimental strength was adopted as the material property of concrete and WFRP reinforcement. Concrete was tested at 28 days as shown in Table 2 and Table 3 shows the material properties of longitudinal bars (from manufacturer) and WFRP shear links.

Table 2. Concrete strength at 28 days

Mean cubic strength $f_{\text {cm, cube }}(\mathrm{MPa}) \quad 35.8$

Calculated mean cylinder strength fcm (MPa) 28.6 
Table 3. Tensile properties of WFRP reinforcement bundles and Aslan bars

\begin{tabular}{cccccc}
\hline Reinforcement & $\begin{array}{c}\text { Cross section } \\
\text { area per unit } \\
(\mathrm{mm} 2)\end{array}$ & $\begin{array}{c}\text { Ultimate } \\
\text { load } \\
(\mathrm{kN})\end{array}$ & $\begin{array}{c}\text { Ultimate } \\
\text { strength } \\
(\mathrm{MPa})\end{array}$ & $\begin{array}{c}\text { Ultimate } \\
\text { strain } \\
\varepsilon u(\%)\end{array}$ & $\begin{array}{c}\text { Elastic } \\
\text { Modulus } \\
\mathrm{E}(\mathrm{GPa})\end{array}$ \\
\hline Transverse WFRP & 4.28 & 5.6 & 1314 & 1.25 & 105 \\
Longitudinal bar & 71.26 & 154 & 2172 & 1.75 & 124 \\
\hline
\end{tabular}

\section{TEST RESULTS}

Three types of failure modes (diagonal tension shear, shear compression, and flexural debonding) were observed as expected in the tests, as summarised in

The shear capacities of tapered beams were greatly enhanced by WFRP. Compared with T1, the specimen without shear reinforcement, the shear capacities were increased ranging from $95 \%$ to $250 \%$, according to Error! Not a valid bookmark selfreference..

Table 4 and Figure 4. Specimen T5-2 reached 95kN when hydraulic jack reached its maximum stroke. Upon reapplication of the load, T5-2 failed at $89 \mathrm{kN}$.

Three failure modes had different characteristics. Diagonal tension failure of specimen T1 and T2-1 was initiated by the major shear crack propagating from the inside edge of the support to the loading plate. Failure was characterised by splitting the concrete web in shear span and rupture of shear reinforcement for T2-1 which was transversely reinforced.

Specimen T2-2, T3-1, T3-2, T5-1 and T5-2 failed in shear compression failure. Characteristic of this failure mode is that the compression zone at the outer edge of loading plate crushed first and enlarged the diagonal tension crack. Final failure was initiated by concrete crushing accompanied by load dropping and rupture of the shear reinforcement. For the specimens failed in this mode, they had very similar failure load around $95 \mathrm{kN}$.

T4 failed in debonding flexural failure. The concrete at the compression zone at the outer edge of loading plate crushed first and the curvature of the beam were increased by the concrete crush. Then the longitudinal bars were pulled-out from the support area and the specimen failed. 


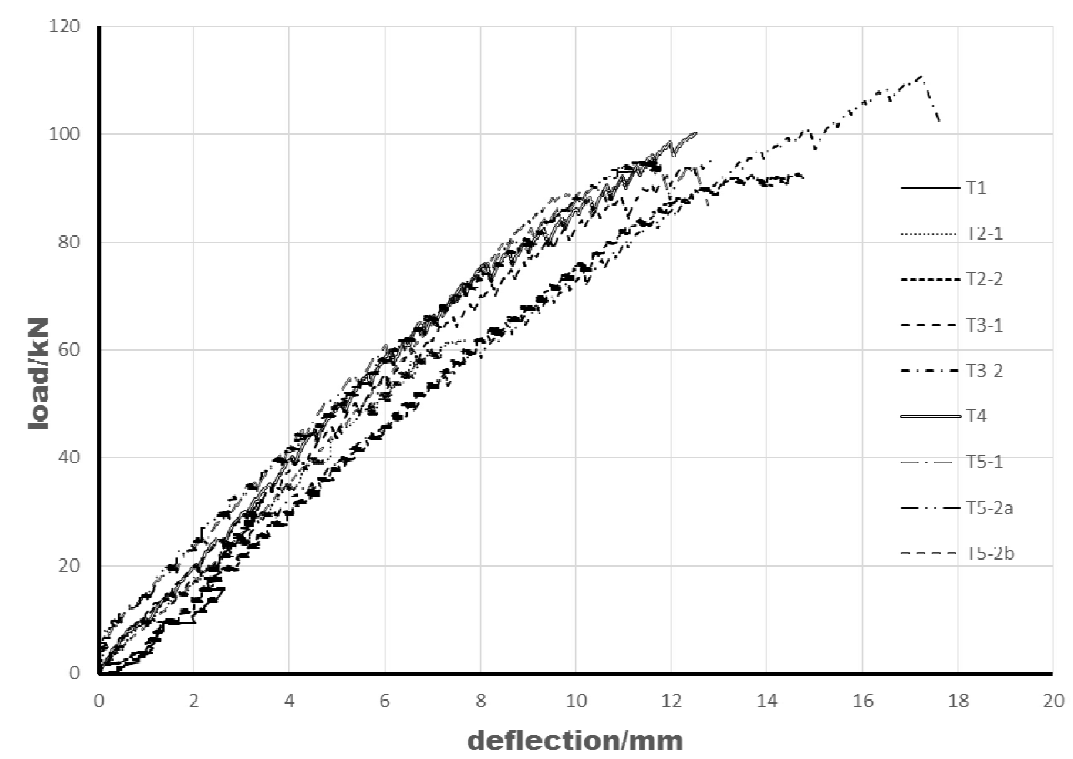

Figure 4. Load and deflection curve of the specimens

The shear capacities of tapered beams were greatly enhanced by WFRP. Compared with T1, the specimen without shear reinforcement, the shear capacities were increased ranging from $95 \%$ to $250 \%$, according to Error! Not a valid bookmark selfreference..

Table 4. Summary of tapered beam test results

\begin{tabular}{cccccc}
\hline Specimen & $\begin{array}{c}\text { Flexure } \\
\text { cracking load } \\
(\mathrm{kN})\end{array}$ & $\begin{array}{c}\text { Load of } \\
\text { inclined shear } \\
\text { crack }(\mathrm{kN})\end{array}$ & $\begin{array}{c}\text { Peak applied } \\
\text { load } \\
(\mathrm{kN})\end{array}$ & $\begin{array}{c}\text { Failure } \\
\text { mode }\end{array}$ & $\begin{array}{c}\text { Deflection of loading } \\
\text { point before failure } \\
(\mathrm{mm})\end{array}$ \\
\hline T1 & 10 & 14 & 31.6 & $\mathrm{DT} 1$ & 6.9 \\
$\mathrm{~T} 2-1$ & 10 & 44 & 61.9 & $\mathrm{DT}$ & 8.3 \\
T2-2 & 10 & 42 & 92.6 & $\mathrm{SC} 2$ & 14.8 \\
T3-1 & 15 & 45 & 94.9 & SC & 14.1 \\
T3-2 & 10 & 25 & 110.8 & SC & 18.7 \\
T4 & 10 & 40 & 100.3 & FD3 & 13.2 \\
T5-1 & 10 & 40 & 94.0 & SC & 12.8 \\
T5-2a & 10 & 30 & 94.9 & & 11.6 \\
T5-2b & $\mathrm{N}$ & $\mathrm{N}$ & 89.0 & SC & 10.3 \\
\hline
\end{tabular}

1: diagonal tension shear failure; 2 : shear compression failure; 3 : flexural debonding failure; ${ }^{\mathrm{a}}$ : first test of specimen $5-2$; ${ }^{\text {b}}$ : second test of specimen 5-2.

\section{ANALYSIS AND DISCUSSION}

\section{Prediction calibration}

For codified predictions, the vertical component of the tensile force of longitudinal bars, $V_{t d}$, were added in the shear capacity predictions. The shear capacity is the sum of the shear resistance calculated at critical section, $V_{f}$, and $V_{t d}$, as shown in Figure 5. For MCFT model predictions, the predictions were made based on the corner strength of the shear links as shown in Equation 1. The shear response of the critical sections was 
calculated with the actual shear stresses (Yang et al., 2015) of variable depth beams (Paglietti and Carta, 2009) and normal tensile strains. The shear capacity was then calculated as the sum of $V_{f}$ and $V_{t d}$.

Equation 1 (Lee, Ko and Lee, 2014)

$\frac{f_{f b}}{f_{f u}}=0.02 \frac{R}{d_{f i}}+0.47 \leq 1.0$

Where $f_{f b}$ is the strength of the FRP shear links at the corner; $f_{f u}$ is the tensile strength of the straight part of the shear links; $R$ is the radius of the corner; $d_{f i}$ is the equivalent diameter of the shear links.

The comparisons between predictions and test result are shown in Table 5. ACI 440 and CSA 806 gave very conservative predictions while MCFT predictions was accurate specially for the specimens with high reinforcement ratios including T3-1, T3-2, T4 and T5-1. But both the codified method and MCFT rely on the reinforcement ratio to consider shear reinforcement and the influence of different WFRP reinforcement patterns were neglected. While the importance of the shear reinforcement pattern is highlighted by the $50 \%$ increase of T2-2's shear capacity compared with T2-1, as shown in

The shear capacities of tapered beams were greatly enhanced by WFRP. Compared with $\mathrm{T} 1$, the specimen without shear reinforcement, the shear capacities were increased ranging from $95 \%$ to $250 \%$, according to Error! Not a valid bookmark selfreference..

Table 4 and Table 5.

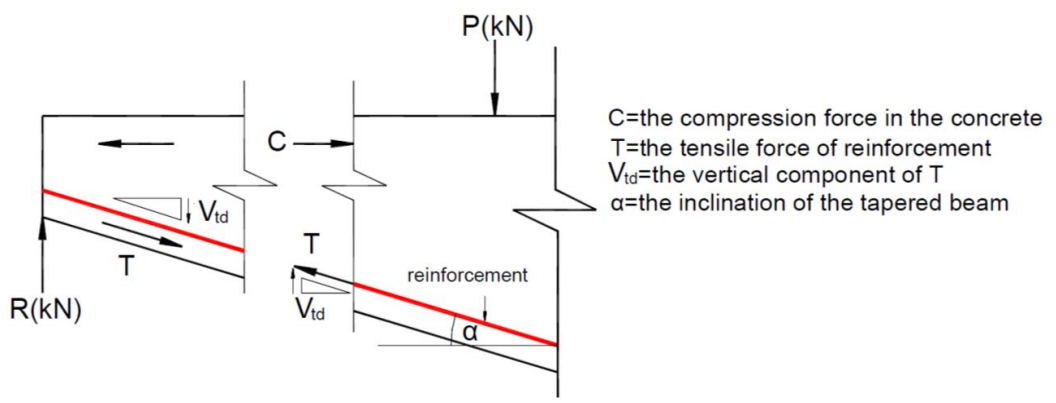

Figure 5. Effect of draped longitudinal reinforcement in a tapered RC beam

Table 5. Comparison between test results and predictions

\begin{tabular}{|c|c|c|c|c|c|c|c|c|}
\hline \multirow[t]{2}{*}{ Specimen } & \multirow{2}{*}{$\begin{array}{c}\text { Test } \\
\text { results } \\
P_{t} \\
(\mathrm{kN})\end{array}$} & \multirow{2}{*}{$\begin{array}{c}\text { Bending } \\
\text { capacity } \\
P_{b} \\
\text { prediction } \\
\quad(\mathrm{kN})\end{array}$} & \multicolumn{6}{|c|}{ Shear capacity $(\mathrm{kN})$} \\
\hline & & & $\begin{array}{l}\text { ACI } \\
\text { prediction } \\
P_{A C I}\end{array}$ & $P_{A C I} / P_{t}$ & $\begin{array}{l}\text { CSA } \\
\text { prediction } \\
P_{C S A}\end{array}$ & $P_{C S A} / P_{t}$ & $\begin{array}{l}\text { MCFT } \\
\text { prediction } \\
P_{M C F T}\end{array}$ & $\begin{array}{l}P_{M C F T} / \\
P_{t}\end{array}$ \\
\hline $\mathrm{T} 1$ & 31.6 & 82.2 & 13.2 & $42 \%$ & 17.6 & $56 \%$ & $-{ }^{\mathrm{a}}$ & $-^{\mathrm{a}}$ \\
\hline $\mathrm{T} 2-1$ & 61.9 & 82.2 & 35.9 & $58 \%$ & 32.0 & $52 \%$ & 41.9 & $67 \%$ \\
\hline T2-2 & 92.6 & 82.2 & 35.9 & $39 \%$ & 32.0 & $36 \%$ & 42.6 & $46 \%$ \\
\hline
\end{tabular}




\begin{tabular}{ccccccccc} 
T3-1 & 94.9 & 82.2 & 58.1 & $61 \%$ & 46.2 & $49 \%$ & 91.1 & $96 \%$ \\
T3-2 & 110.8 & 82.2 & 58.4 & $53 \%$ & 46.4 & $42 \%$ & 92.3 & $83 \%$ \\
T4 & 100.3 & 82.2 & 81.0 & $81 \%$ & 61.2 & $61 \%$ & 124.7 & $82 \%$ \\
T5-1 & 94.0 & 82.2 & 58.1 & $62 \%$ & 46.2 & $49 \%$ & 92.1 & $98 \%$ \\
T5-2 & 94.9 & 82.2 & 40.4 & $43 \%$ & 35.0 & $37 \%$ & 56.1 & $59 \%$ \\
\hline
\end{tabular}

${ }^{\mathrm{a}}$ : MCFT model cannot give predictions for unreinforced concrete; ${ }^{\mathrm{b}}$ : the ratio is calculated by the bending capacity prediction and test results.

\section{Influence of WFRP shear reinforcement}

The shear reinforcement ratio and shear reinforcement pattern were found to influence the shear capacity of the specimens. With the increase of shear reinforcement ratio, the failure mode changed from diagonal tension failure to shear compression failure and ultimate capacities increased. With very high shear reinforcement ratio, T4 reached bending failure.

When shear failure happens, steel shear links going through the shear crack may all reach their yielding point and there will be no difference in the loads carried by each of the shear links. This behaviour is not seen in WFRP due to the linear elastic nature of the material. Once some of the WFRP links reached their rupture load, the shear failure may happen with other shear links carrying less load than their ultimate capacity. The shear reinforcement pattern therefore plays an important role in the shear performance.

With same reinforcement ratio, specimen with denser pattern with thinner links reached higher load, as shown by comparing T2-1 with T2-2, and T3-1 with T3-2. More distributed patterns not only have a greater number of WFRP legs crossing potential shear cracks but also may supply better confinement at the compression zone.

Comparing T5-1 and T5-2, it is also found that with less reinforcement, a good WFRP pattern can supply similar shear capacity even though it seems the concrete strength restrained the failure load of shear reinforcement cage. Although the optimal pattern is not found yet but it shows that there is great potential to reduce material usage by optimising the shear reinforcement pattern.

\section{CONCLUSION AND FUTURE WORK}

\section{Conclusion}

Eight tapered beams with WFRP reinforcement were design and tested. The codified design method and MCFT model were calibrated with the test results. The shear performance of the specimens was analysed considering the shear reinforcement ratio and pattern.

The application of WFRP in tapered beams with optimised geometry is successful and the WFRP cages were easy to construct. All specimens failed with the expected failure mode and WFRP increased the shear capacity of the tapered concrete beams by $95 \%$ to $250 \%$ compared to the plain concrete specimen. The MCFT model was best able to predict the shear performance of the tapered beams using WFRP among three methods. Shear reinforcement patterns are shown to heavily influence the shear capacity of the specimens and there is therefore great potential to optimise the shear reinforcement pattern, minimising the WFRP length to achieve maximum shear capacity. 


\section{Future work}

Further research needs to be done to investigate how to design the optimal WFRP shear reinforcement pattern. In addition, the MCFT model need to be revised to adapt to different WFRP patterns. With the successful application in tapered beam, more experimental research needs to investigate the application of WFRP in full-size fabric formed concrete $\mathrm{T}$ beams.

\section{ACKNOWLEDGEMENT}

The authors acknowledge and are grateful for the support of the BRE CICM (www.bath.ac.uk/bre), the University of Bath, and the China Scholarship Council who collectively fund the $\mathrm{PhD}$ position that has resulted in this work.

\section{REFERENCES}

ACI 440 (2007). Guide for the Design and Construction of Structural Concrete Reinforced with FRP Bars. American Concrete Institute.

Bailiss, J. (2006) 'Fabric-formed concrete beams: Design and analysis', MEng Thesis, Department of Architecture and Civil Engineering, Bath, University of Bath.

CAN/CSA-S806-12 (2012). Design and construction of building structures with fibrereinforced polymers, Canadian Standards Association, Ontario, Canada.

Lee, C., Ko, M. and Lee, Y. (2014) 'Bend Strength of Complete Closed-Type Carbon Fiber-Reinforced Polymer Stirrups with Rectangular Section', Journal of Composites for Construction, 18(1).

Orr, J. J., Darby, A. P., Ibell, T. J., Evernden, M. C. and Otlet, M. (2011) 'Concrete structures using fabric formwork', Structural Engineer, 89(8), pp. 20-26. doi: 10.1007/s13398-014-0173-7.2.

Paglietti, A. and Carta, G. (2009) Remarks on the Current Theory of Shear Strength of Variable Depth Beams, The Open Civil Engineering Journal. Available at: http://benthamopen.com/openaccess.php?tociej/articles/V003/28TOCIEJ.htm (Accessed: 30 December 2016).

Vecchio, F. J. and Collins, M. P. (1986) 'The modified compression-field theory for reinforced concrete elements subjected to shear', ACI Journal Proceedings, pp. 219-231. doi: 10.14359/10416.

Veenendaal, D., West, M. and Block, P. (2011) 'History and overview of fabric formwork: Using fabrics for concrete casting', Structural Concrete, pp. 164177. doi: $10.1002 /$ suco.201100014.

Yang, Y., Orr, J., Ibell, T. and Darby, A. (2015) 'Shear strength theories for beams of variable depth', (August). Available at: http://opus.bath.ac.uk/ (Accessed: 30 December 2016). 